Check for updates

The BMJ

fgodlee@bmj.com Follow Fiona on Twitter @fgodlee

Cite this as: BMJ 2021;375:n2668 http://dx.doi.org/10.1136/bmj.n2668 Published: 04 November 2021

\title{
Covid 19: A strong pandemic response relies on good data
}

\section{Fiona Godlee editor in chief}

Many things are needed to get the world through this pandemic: one of them is high uptake of vaccination. For this we need strong public confidence in the vaccines, justified by reliable and transparently accessible trial data. We need clear messaging, good systems of delivery, and globally equitable distribution in line with the true burden of disease.

How well are we doing on these various fronts? It's fair to say that things could be better. We are right to celebrate the successful delivery of vaccines by healthcare workers around the world. We are also right to celebrate the work of the scientists who developed the covid vaccines, the companies that have manufactured and delivered them, and the vaccines' undoubted effect on rates of death and illness. We must also recognise the urgent pressure under which the scientists were working, as deaths soared and countries shut down. Would we then be wrong to insist that the best standards of research integrity should nonetheless prevail (https://blogs.bmj.com/bmj/2021/01/04/peter-doshipfizer-and-modernas-95-effective-vaccines-we-needmore-details-and-the-raw-data)? ${ }^{1}$

Sadly, a picture is emerging, from one commercially contracted trial centre at least, of poor research conduct, lax data management, and a lack of regulatory oversight. Reports by a former employee of the contract research organisation that enrolled patients into Pfizer's pivotal vaccine trial raise serious questions about the safety of participants and integrity of the data (doi:10.1136/bmj.n2635). ${ }^{2}$

We don't yet know the impact of these problems on the trial as a whole. Were this company's trial centres a single rotten apple, or do they represent a wider problem? Certainly the failures of regulatory oversight seem endemic: the FDA inspected only nine of the Pfizer trial's 153 study sites, and, despite specific concerns being raised about this centre, it was not one of those inspected. We are right to ask how science fares when those who raise questions are fired.

Will vaccine passports help, or are they a technological distraction from efforts to achieve global vaccination (doi:10.1136/bmj.n2571)? ${ }^{3}$ What more should we do to encourage vaccine uptake during pregnancy (doi:10.1136/bmj.n2377)? ${ }^{4}$ And how good are the data on deaths from covid? Before the pandemic, an estimated $40 \%$ of deaths worldwide were not registered, with under-reporting most marked in low income and fragile settings (doi:10.1136/bmj.n2239). ${ }^{5}$ The pandemic is unlikely to have made this better. Why does it matter? Because death numbers are the basis for evaluating the progress of the pandemic and the effectiveness of public health interventions. They are the basis for weighing up complex trade-offs in efforts to control transmission and for holding governments to account.
And they are what drives allocation of resources, including vaccines, on the basis of accurate estimates of the global burden of disease.

If we are to achieve a scientifically robust and globally equitable response to the pandemic we must invest in good data.

Doshi P. Pfizer and Moderna's "95\% effective" vaccines-we need more details and the raw data. BMJ Opinion. Jan 2021.

https://blogs.bmi.com/bmi/2021/01/04/peter-doshi-pfizer-and-modernas95-effective-vaccines-we-need-more-details-and-the-raw-data.

2 Thacker PD. Covid-19: Researcher blows the whistle on data integrity issues in Pfizer's vaccine trial. BMJ2021;375:n2635. doi: 10.1136/bmi.n2635 pmid: 34728500

3 Sleat D, Innes K, Parker I. Are vaccine passports and covid passes a valid alternative to lockdown?BM/2021;375:n2571doi: 10.1136/bmi.n2571.

4 Abbas-Hanif A, Modi N, Smith SK, Majeed A. Covid-19 treatments and vaccines must be evaluated in pregnancy. BMJ2021;375:n2377. doi: 10.1136/bmj.n2377 pmid: 34649863

5 Whittaker C, Walker PGT, Alhaffar M, etal. Under-reporting of deaths limits our understanding of true burden of covid-19. BMJ 2021;375:n2239. doi: 10.1136/bmj.n2239 pmid: 34642172

This article is made freely available for use in accordance with BMJ's website terms and conditions for the duration of the covid-19 pandemic or until otherwise determined by BMJ. You may use, download and print the article for any lawful, non-commercial purpose (including text and data mining) provided that all copyright notices and trade marks are retained. 